\title{
The Need to Consider the Complexity of Human Behaviour when Engineering Technical Systems for Risk Prevention
}

\author{
Sebastian Festag ${ }^{1 *}$ \\ 1 Hekatron, Head of Applied Science, Wuppertal University, Germany
}

\begin{abstract}
Safety science pursues the aim of preventing or reducing as much as possible damage caused by hazards, on a methodical and systematic basis. An important part of this is safety engineering, which deals with the hazards of socio-technical systems. Safety engineering has successfully established itself and differentiated into many fields. All areas of our lives involve questions of hazards, so safety science and safety engineering must continually develop in the course of time. Each dangerous situation has its special and general characteristics. The human factor is a general subject and plays an important role in virtually all hazards and is decisive for the functioning of socio-technical systems. In previous eras, hazards by technical systems were frequently the result of failure of materials or components. The majority of safety problems in the current situation are related to human beings. This is not due to the "deficiency" of human beings, however, but is rather a result of ignoring the complexity of their behaviour in the engineering of (technical) systems. This situation is explained in the present article on the basis of studies dealing with the cause-analysis of hazards in the context of different technical systems.
\end{abstract}

Keywords: Human behaviour, human factor, complexity, socio-technical systems, final closure of a production-site, false alarms, installed fire detection and fire alarms systems.

\section{Introduction: The human factor - risk or chance?}

Safety science is an autonomous and self contained discipline. It combines multiple elements from other disciplines into an interdisciplinary approach relating to hazards and risks and pursues the aim of preventing damage caused by hazards, or reducing them as much as possible, on a methodical and systematic basis (e.g. [1]). An important part of safety science is safety engineering, which deals with the hazards of socio-technical systems and their control (e.g. [2]). This is a continuous advantage, which accompanies the consequences of the progress of our society. Technical development affects the subject of hazards in various ways. Because the technical development avoids hazards by means of new solutions (technical safety) and at the same time leads to hazards of its own - in the sense of collateral damage - which demand solutions (safety of technology), although this interpretation is to be understood in the broadest possible sense (safety techniques) ([3], [4]). This all-embracing is known as the field of safety engineering and has developed into a successful academic discipline. With the increasing specialisation, safety engineering has been divided into many fields, such as occupational health, plant safety, fire protection (engineering) and explosion protection, reliability analysis and risk management, environmental protection, civil protection and disaster 
control, quality management and security - an field which it is becoming more important to integrate into safety engineering due to the human factor. Risks (such as accidents, occupational diseases, stress, bagatelles, technical defects, production stoppages or attacks) show special and general characteristics across all fields, although the casespecific elements are often predominant. The human factor is a general subject. This includes all organisational, environment and task-specific factors, and individual and general characteristics of human beings which influence their dealings with systems and technical components (according to [5] and [6]; modified). In short: The human factor concerns the mutual influences and dependencies between human beings and their (often technical) environment and the risks and chances resulting from it.

The ways humans behave and react play an important role - in a positive and negative sense - for the functioning of technical systems and in the majority of safety problems in the here and now as a safety objective and within the course of the hazards, from its origin to its counteractive measures. Studies [7] show that previously hazards by technical systems were frequently the result of material or component failures. The majority of safety problems in the current risk situation are related to human beings, approx. 95\% - depending on the state of civilisation and region and despite numerous ergonomic programmes (it can be partly explained by a change in awareness). In this context, human beings becomes the alleged cause of accidents - which is equivalent to an misdiagnosis - and is declared the weakest point in the system (human error) and his interventions into the system processes are ruled out as far as possible on this basis. In the framework of a series of investigations, several studies were carried out in different areas, in order to work out further details about the human factor and the cause-effects of risks connected with socio-technical systems. The present article describes a selection of studies from industrial environments.

\section{Selected studies on the human factor}

All the studies selected here deal with real situations in socio-technical systems and look at the course of risks, taking the human factor into the focus. In the following description each of the selected studies is divided up into the sections introduction, method, results and conclusion in the context of the present topic.

\subsection{Investigation of the final closure of a production-site}

The study described here based on [8] deals with the analysis of the final closure of a production-site located in Germany (see [9]). It must be pointed out that investigations of this kind into real situations are rare. The company management is occupied in economically tense times with handling the problems and while doing this it often shies away from insight into the production processes - partly out of fear of its own "mistakes" will be exposed.

After several entrepreneurial mergers and takeovers, the analysed production-site belonged to a globally operative concern and at the time of the production-site closure found itself in an economically tense situation which affected round about 300 employees. Before the site's closure, it was intended to overcome the situation by developing a new product. After a period of adjustment, this product was manufactured on a stable basis and was successfully introduced onto the market. Employees of the plant were called upon by the group management to transfer the product characteristics to a newly founded affiliated production-site abroad - with larger machines and at the same time fewer jobs and implicitly high expectations of profitability. During this transferral, the group management adopted the resolution to close the analysed production-site. Initially, however, the delaying of the resolution was left open depending on the production results.

The closure phase of the production-site was accompanied over a period of around 13 months. Figure 1 shows some important events during the closure phase of the production-site in a chronological order.

As part of this, we have evaluated accidents, plant inspections, interviews, monthly announcements of the company management to the employees, statements from the site management to the public, and numerous production and safety parameters before and during the closure phase were analysed and compared with each other. The quantitative analysis of the safety situation is based on - among other things - 92 non-reportable accidents (more than 1 and less than 4 days of incapacity to work), reportable work accidents (with more than 3 days of incapacity to work), accidents at work suffered at the 


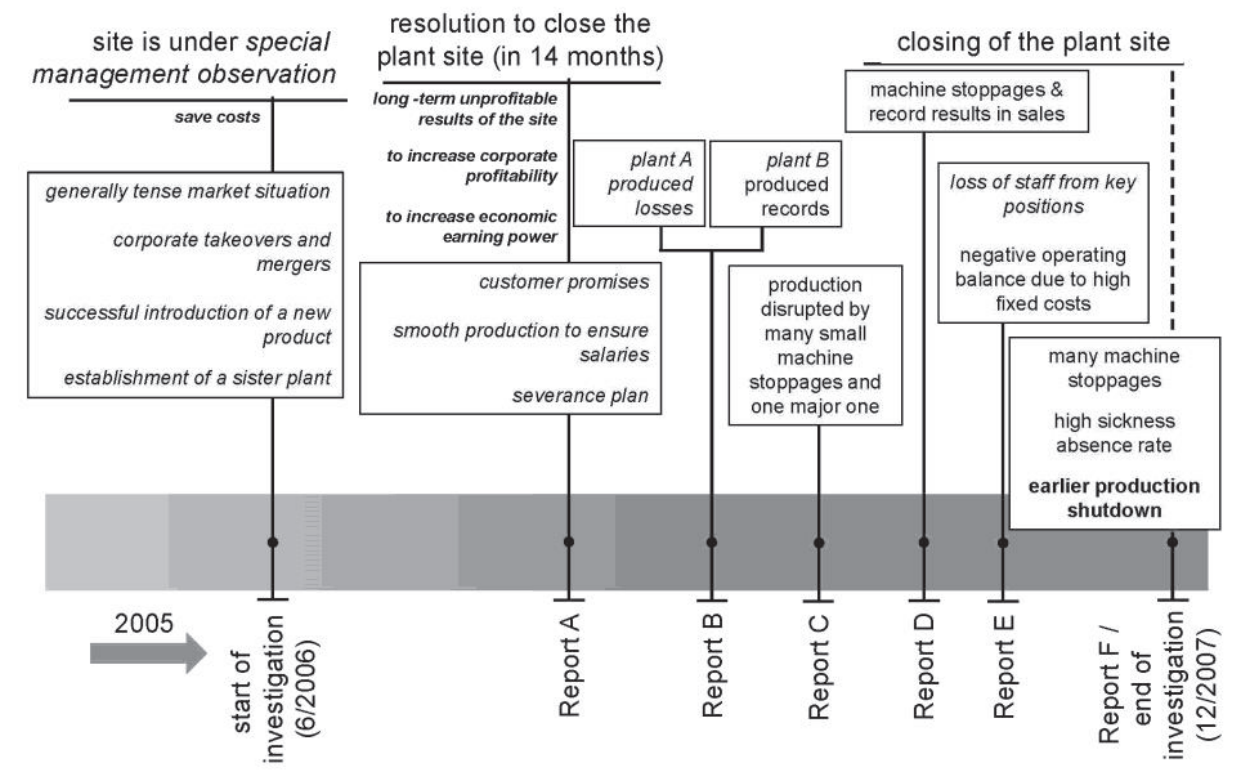

Fig. 1: Chronology of the final closing of the production-site [9].

premises of a contractor company and commuting accidents with 653 calendar days of incapacity before and 88 accidents with 418 calendar days of incapacity during the closure phase.

In summary, it can be seen from the chronology of problems and the quantitative analysis of the accidents and absence times that after the announcement of the site's closure there was initially a decrease in the number of accidents in comparison with the same period the previous year. With the passing of time, the number of accidents increase beyond its usual proportions, see Fig. 2. In this development, it is to be taken into account that fewer employees were employed in the productionsite.

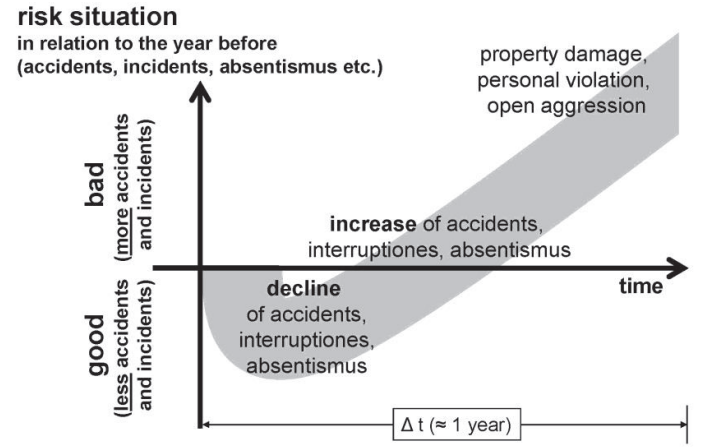

Fig. 2: Simplified risk situation during the closure phase of the production-site [9].
The fall in accident key figures at the start of the closure phase can be interpreted as hope of the employees of a turnaround, because the delaying of the management decision was left open, depending on the operating result. The rise in the accident key figures over the course of time can be interpreted as resignation and frustration, as the finality of the decision became increasingly recognisable. At the end of the production-site closure, there were no longer enough employees working and production had to be ceased ahead of time. Over the course of time, the situation intensified. There were more accidents, production disruptions and machine stoppages. On top of this, there were damages to property and attacks on people resulting in personal injury.

Although the technical and organizational marginal conditions remained the same, the approach and decisions of the management, triggered reactions by the employees via complex psycho-social mechanisms, which initiate a very wide range of safety and security problems with substantial damages, such as damages to property, work accidents and incidents, production disruptions, machinery stoppages. A more detailed portrayal of the results and conclusions can be found in [9].

\subsection{Meta-analysis of false alarms due to fire detection and alarm systems}

Another study [10] deals with system technologies 
for the automatic detection of fires (installed fire detection and fire alarm systems, FDAS). This study is a meta-analysis. In this, several primary studies (of our own) on the ratio of false alarms in the use of FDAS are summarised ([11], [12], [13]), in order to provide, a quantitative statement on the magnitude of the problem and the background of its activations. This meta-analysis is here in the following outlined in its key facts and the importance of the human factor. The details of the calculation and the primary studies upon which the meta-analysis is based are explained in detail in [10].

Fire brigades receive a large number of fire alarms in which, when the fire brigade arrives, there is no (longer) indication of a fire [11]. It is a "false alarm". Manual as well as automatic means of transmission the alarm are affected by false alarms. Sensitive detection of hazards, such as is provided by FDAS is often accompanied by an increased number to false alarms. Until our own work, the concrete ratio of false alarms in Germany was unknown and was more estimated than based on hard facts. In order to achieve the availability of shared and comparable data, in addition to the absolute number of false alarms (nFDAS,FA) in a defined area (e.g. area of intervention of a fire brigade) and period of time (e.g. a year), several reference values (depending on authoritativeness and availability) have been derived in the meta-analysis:

$$
\mathrm{FA}_{1}=\mathrm{n}_{\mathrm{FDAS}}, \mathrm{FA} / \mathrm{n}_{\mathrm{FO}}
$$

Definition: False alarm ratio based on the number of false alarms of installed (and connected) FDAS in relation to the number of all fire-fighting operations (all fire alarms, activations; real and non-real fire conditions; nFo).

$$
\mathrm{FA}_{2}=\mathrm{n}_{\mathrm{FDAS}}, \mathrm{FA} / \mathrm{n}_{\mathrm{FO}, \mathrm{B}}
$$

Definition: False alarm ratio based on the number of false alarms of installed (and connected) FDAS in relation to the number of all fire-fighting operations (fire alarm activations) in buildings ( $\mathrm{n} F \mathrm{~B}, \mathrm{~B})$.

$$
\mathrm{FA}_{3}=\mathrm{n}_{\mathrm{FDAS}}, \mathrm{FA} / \mathrm{n}_{\mathrm{FDAS}, \mathrm{I}}
$$

Definition: False alarm ratio based on the number of false alarms of installed (and connected) FDAS in relation to the number of installed (and connected)
FDAS (nFDAS,I).

$$
\mathrm{FA}_{4}=\mathrm{n}_{\mathrm{FDAS}}, \mathrm{FA} / \mathrm{n}_{\mathrm{FDAS}}
$$

with

$\mathrm{n}_{\mathrm{FDAS}}=\mathrm{n}_{\mathrm{FDAS}}, \mathrm{FA}+\mathrm{n}_{\mathrm{FDAS}} \mathrm{RF}$

Definition: False alarm ratio based on the number of false alarms of installed (and connected) FDAS in relation to the number of all fire alarm activations caused by installed (and connected) FDAS (real and non-real fire conditions by FDAS; nFDAS).

On this basis, five analyses in the context of false alarm ratio in the use of FDAS were appraised. The first analysis is based on available and comprehensible annual statistics of the fire brigades from 11 federal states in Germany. In the second analysis, the intervention data of 3 fire brigades, each from a different federal state, were analysed in detail through the years 2010 to 2012. In the third analysis, the entirety of the intervention data from one fire brigade was completely analysed for the years 2006 to 2011. The data comprised a total of 2,827 interventions, with 550 real fire-fighting operations. In this analysis, extreme values were adjusted, because small fire brigade units - that belonged to the fire brigade analysed - had false alarm rates between 0 and $100 \%$ due to the low absolute number of cases. In the fourth analysis, intermediate results from the pilot project "Fire loss statistic" of the German Fire Protection Association (vfdb) was analysed as regards the occurrence of false alarms due to FDAS. In the fifth analysis, the intervention data from one professional fire brigade on FDAS for the years 2003 to 2010 were analysed. The results of the studies are shown in Fig. $\mathbf{3}$ and can be summarised as follows [10]:

- The first analysis of the annual statistics of the federal states shows on average a false alarm ratio from installed FDAS in relation to the number of fire-fighting operations of $F A_{1}=46.48 \%$.

- The second analysis found on average a false alarm ratio of $F A_{1}=38.28 \%$. On average, the false alarm ratio of installed FDAS in relation to all fire alarms triggered by installed FDAS is equal to a value of $F A_{4}=87.63 \%$.

- The third analysis results in a false alarm ratio of installed FDAS in relation to its fire-fighting operations of $F A_{1}=23.18 \%$ and, in relation to all alarms triggered by installed $F D A S$, of $F A_{4}=65.39 \%$. 


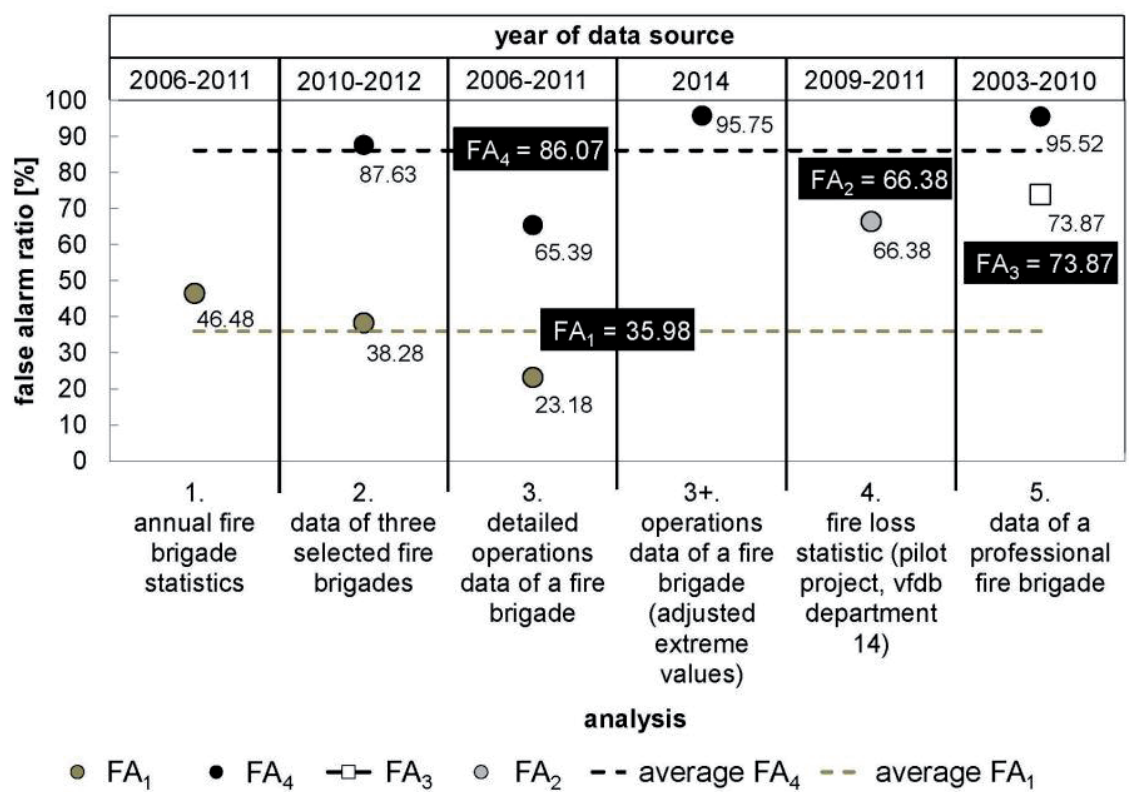

Fig. 3: False alarm ratio of installed FDAS in Germany in a summarized form [10].

- The vfdb pilot project results in a false alarm ratio of installed FDAS in relation to the number of fire alarms in buildings of $F A_{2}=66.38 \%$.

- The fifth analysis shows a false alarm ratio in relation to the number of installed FDAS of $F A_{3}=73.87 \%$. From 2003 to 2010, a decreasing trend be observed, with a reduction of $13 \%$. The false alarm ratio $\mathrm{FA}_{4}$ is on average $95.52 \%$.

If all results are averaged once again, we get $F A_{1}=35.98 \%, F A_{2}=66.38 \%, F A_{3}=73.87 \%$, and $F A_{4}=86.07 \%$ (the informative value increases in the same order).

At first glance, a high rate of false alarms seems to be attributable to insufficiently developed technology. In actual fact, however, human behaviour plays a central role here too. With FDAS false alarms can occur in different ways. In Germany, in practice, they are essentially divided up into three groups - similar approaches exist in e.g. the United Kingdom, Austria and Switzerland. The first group of false alarms comprises the "technical defects", which are also referred to as "blind alarms" or unwanted alarms. They are based on defects in the technical devices and/or components (e.g. sensors, warning indicators, incident rooms or cables). It must be noted that, in practice, it is customary to explain the "cause" as a technical defect in cases of doubt. For this reason, the percentage of technical defects is probably higher than the real figure [10]. The second group is that of "deceptive alarms". Here, an alarm is triggered when there is no real fire, although the technical devices are working properly in these cases. However, the sensors react to parameters of fire-like phenomena (e.g. water vapour, dust, and solar radiation) - inappropriate handling is normally the cause in these cases. The third group contains malicious and good intent alarms caused by people. The third group resembles the deceptive alarms, because, here too, the systems are functioning correctly, but the triggering of the alarm is essentially not due to physical and chemical parameters, as is the case with the deceptive alarms, but is instead obviously to be attributed to human behaviour. The difference between malicious and good intent activities lies in the intention of the person acting. This is often unknown, which is why these forms of triggering can be considered combined in one group. At first glance, human behaviour is only of importance in the occurrence of false alarms in the third group. However, human behaviour plays an important role in all groups (see Fig. 4).

For example, a false alarm in the use of FDAS can take place due to a technical defect because of failure of a material or component failure. The material or component failure can arise due to improper commissioning, workmanship or inadequate checks for which company internal management conflicts are responsible - as discussed in chapter 2.1. Or a 


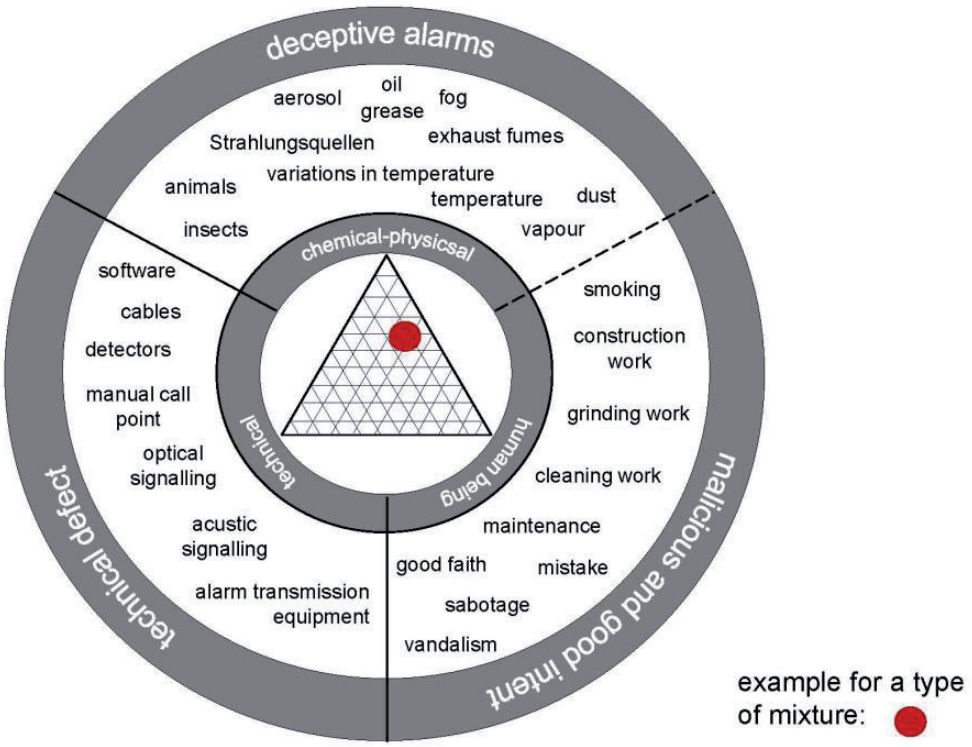

Fig. 4: The mixture of false alarm causes.

spurious alarm is triggered due to an employee's deficient problem awareness, because the fire detectors were not covered during construction works. In the case of malicious alarms, for example, persons trigger manual call points or hold matches underneath fire detectors with the intention of causing losses by triggering them. In the case of false alarms due to good intent, the persons in question alert the fire brigade in an act of good faith (mistake) although, here as well, there is no fire.

\section{Summary: The human being as common denominator}

The present article explains two studies. Both studies deal with hazards and technical systems. In the first case, which concerns the safety of a production process, hazards - in the sense of collateral damage - arise during the attempt to solve a tense situation. The second case concerns hazards arising as side effects of the use of safety technologies, which are used to protect sociotechnical systems in a cross-section of application. Both cases outline how hazards arise associated with the human factor.

In the analysis of the processes during the production-site closure, it was shown that the management resolutions are the driving forces for various hazards arising from the human factor. There were accidents, production disruptions, machine stoppages, production interruptions and personal attacks. Safety and security problems thus arose. The technical boundary conditions are essentially comparable to those in the situation before the closure phase. This led to the conclusion that the hazards and problems are linked to the behaviour of the employees. They react to the situation in very different ways and often emotionally. The management does not take this state of affairs sufficiently into account in its approach and its resolutions. One should mention here that managers are, in general, not trained for such processes. This is also the case for safety officers. Here, the situation is made even more difficult by the fact that work and resources are often severely limited in such phases - although the situation involves increased requirements.

At first glance, the analysis of the problem of false alarms of FDAS is a technical subject. The analyses show, however, that this problem stems basically from human behaviour. To date, insufficient attention has been paid to this state of affairs.

In many safety and security problems the accident cause is often referred to - in layman's terms - as "human error". Actually, phenomena of hazards, as we have seen here, are frequently the result of man-made (artificial) conditions, which ignore the complexity of human functioning in many cases, due to modern approaches. Human beings are more 
than physiological "system-components" based on rational processes. Emotions play a decisive role in context with psycho-social mechanisms (e.g. [14]). This state of affairs has not yet been taken sufficiently into account by many different technical - artificial - systems, which provokes hazards and failures.

\section{Conclusions}

Human ways of behaving and reacting play a prominent role, in a systemic way, in the prophylaxis and therapy of technical safety and security problems. The influences arise in many places and often trigger far-reaching cascade effects within multifactorial cause-effect relationships, which makes the situation extremely complex. The human factor is decisive for the origin and course of accidents and the effectiveness of protection measures. The human factor needs to be taken more into account in the engineering of technical systems and the strategies of safety and security measures. Above all, emotions have a central function via psychosocial mechanisms. The human being must be seen as a whole.

The human being is not just a risk, but also a chance. This sounds banal. But it is worth noticing, because this is often overlooked in the enthusiasm of technical progress. In the encounter with technical solutions, machines and systems, physically describable parts and processes come into effect. In the integration of the human factor it is often expected that people will behave in the same way. It is this perspective that fosters a majority of current problems. The causes of hazards and technical problems do not actually lie in the "deficiency" of human beings (in the immediate environment of the system failure), but they lie in the neglecting of their complexity. This corresponds with a common-cause failure situation [15], in which different safety and security problems have a common trigger. There is a need of a greater integration of the human behaviour, especially emotions - into system engineering for risk prevention. Continuation and deepening of the work is necessary.

\section{References and Notes}

[1] Compes, P.C., 1980, Erwartungen der Sicherheitstechnik an die Humanwissenschaft. [Safety Engineering's Expectations of Human Science] In 2. GfS-Sommer-Symposion: Der Mensch als Sicherheitsproblem in technischen Systemen [At the 2nd GfS Summer Symposium: Humans as a Safety
Problem in Technical Systems] (p. 57-78). University of Wuppertal - Gesamthochschule Wuppertal: Gesellschaft für Sicherheitswissenschaft

[2] Ritz, F., 2015, Betriebliches Sicherheitsmanagement Aufbau und Entwicklung widerstandsfähiger Arbeitssysteme [Company safety management - Structure and development of robust work systems], Stuttgart: SchäfferPoeschel Verlag

[3] Festag, S., 2015, Menschliches Verhalten und Risikokompetenz - Fallanalysen [Human Behaviour and Risk Competence - Case Analyses]. In: Sebastian Festag \& Uli Barth (Editor): Risikokompetenz: Beurteilung von Risiken [Risk competence: Risk Assessment]. Schriften der Schutzkommission - Band 7. Bundesamt für Bevölkerungsschutz und Katastrophenhilfe [Report of the Safety Commission - Vol. 7, German Federal Office for Civil Protection and Disaster Control], p. 241-252

[4] Festag, S., 2014, Analyse von Unfallursachen und das Kausalitätsproblem [Analysis of accident causes and the problem of causality]. In: Sebastian Festag (Editor): Unfallursachenanalyse [Accident cause analysis]. XXVIV. Sicherheitswissenschaftliches Symposion der Gesellschaft für Sicherheitswissenschaft. Allgemeine Unfallversicherung Österreich, Forum Prävention, Innsbruck (Austria), 21.05.2014, Berlin: Beuth-Verlag, p. 1-14

[5] AK-MF, 2011, Kompetenzen bezüglich menschlicher Faktoren im Rahmen der Anlagensicherheit (Betreiber, Behörden und Sachverständige). [Responsibilities relating to human factors in the context of plant safety (Operators, authorities and experts)] Leitfaden des Arbeitskreises Menschliche Faktoren der Kommission für Anlagensicherheit beim Bundesministerium für Umwelt, Natur- und Reaktorsicherheit, [Guidelines of the Human Factors Work Group of the Commission for Plant Safety at the Federal Ministry for the Environment, Nature Conservation and Nuclear Safety], Bonn, p. 27

[6] Fahlbuch, B., Meyer, I., Dubiel, J., 2008, Einfluss menschlicher Faktoren auf Unfälle in der verfahrenstechnischen Industrie [Influence of human factors on accidents in process industry]. Bericht, Im Auftrag des Umweltbundesamtes [Report, on behalf of the Federal Environment Agency], Forschungsbericht 20648 300, UBA-FB 001128, Dessau-Roßlau

[7] Hartwig, S., 07/2007, Safety gets real. The Chemical Engineer, Vol. 7, Issue. 793, p. 34-35

[8] Festag S., 2012, Systemsicherheit und menschlicher Faktor: Über das Versagen von Strategien zur Risikobewältigung [System Safety and Human Factor: On the Failure of RiskReduction Strategies]. Dissertation, University Wuppertal

[9] Festag S., Hartwig S., 2016, Consequences of ignoring the complexity of human behaviour for industrial safety and 
security, Chemical Engineering Transactions, 48, 919-924 DOI:10.3303/CET1648154

[10] Festag S., 2016, False Alarm Ratio of Fire Detection and Fire Alarm Systems in Germany - A Meta-Analysis. Fire Safety Journal, Volume 79, Elsevier, pp. 119-126 (DOI: 10.1016/j. firesaf.2015.11.010)

[11] Döbbeling, E.P., Festag, S., Witzigmann, M., 8/2012, Brandschadenstatistik zur Wirksamkeit anlagentechnischer Brandschutzmaßnahmen [Fire loss statistics for the effectiveness of fire protection technologies]. VFDB, Ausgabe 3, S. $123-127$

[12] Schmitz, D., 2013, Untersuchung zur Bestimmung der Größenordnung von Falschalarmierungen von Brandmeldeanlagen [Study to determine the size scale of false alarms of installed fire detection and fire alarm systems]. Bachelor thesis, University Wuppertal

[13] Festag, S., Schmitz, D., 8/2014, Bestimmung der Falschalarmrate von Brandmeldeanlagen [Determination of the Rate of False Alarms by Automated Fire Alarm Systems]. VFDB, 3/2014, pp. 134-141

[14] Gigerenzer, G., 2008, Bauchentscheidungen - Die Intelligenz des Unbewussten und die Macht der Intuition [Emotional decisions - The intelligence of the unconscious and the power of intuition], Goldmann Verlag: Munich

[15] Hartwig, S., 10/2012, Kollektives Sicherheitsversagen - Vom Managementverhalten induzierte Common-Mode-Fehlersituationen in Industrie und Politik [Collective safety failure - common-mode failure situations induced by management behaviour in industry and politics]. Technische Sicherheit, 10, pp. 26-31

\section{Biographical notes}

Sebastian Festag,Dr.-Ing. 03/19/1981, is a Safety Scientist. After apprenticeship as a chemical-technical assistant and the study of safety engineering at the University Wuppertal (BUW) he was scientifically active at the BUW and University of Applied Science Furtwangen (HFU). He received his Dr. Ing. in 2012 in safety engineering at BUW on studies about the human factor. Since 2011 he is head of Applied Science at Hekatron. In this context his research includes industrial safety and security and the effectiveness of safety and security strategies. He has written 2 books, edited 5 books and published a number of scientific articles. Additionally he is active in several associations and working groups. Since 2015 he is president of the GfS e.V. (Gesellschaft für Sicherheitswissenschaft, Society of Safety Sciences), a member of the Executive Committee of the European Societey for Automatic Systems e. V. (EUSAS) and deputy head of department 14 (system technology) of the German Fire Protection Association e.V. (vfdb). 